Article

\title{
Imagination, Indigeneity, and Computation: The SIGGRAPH 2018 Art Gallery
}

\author{
Andres Burbano
}

Department of Design, Universidad de los Andes, Bogotá 111711, Colombia; aburbano@uniandes.edu.co

Received: 21 October 2019; Accepted: 23 January 2020; Published: 10 February 2020

check for updates

\begin{abstract}
This report addresses the SIGGRAPH 2018 Art Gallery (Vancouver, 2018), its curatorial process, the conceptual guidelines, the methodological approaches, and the sources behind it. The gallery has emphasized a transdisciplinary perspective combining creative and critical projects coming from art, science, and technology. The exhibition was one component of the SIGGRAPH conference, and it was built upon five conceptual nodes, in this text, particular attention is paid to the historical node. The SIGGRAPH Art Gallery is an international show that in 2018 included the work of artists, engineers, and scientists from more than twelve countries participating in the exhibition in situ and from other ten countries participating in the online exhibition. In general terms, the dialog between a diverse set of projects is one of the most compelling aspects of the exposition, the participation of Indigenous artists working with digital media represented one of the most challenging and positive elements of the gallery. The theoretical reflections of Friedrich Kittler about the museums and their relationship with computation and information were a permanent source of inspiration. This text is located halfway between a report and a paper. Therefore, some sections are written in the first person.
\end{abstract}

Keywords: SIGGRAPH; SIGGRAPH 2018 Art Gallery; computer art; CAD history; indigenous media art; aboriginal media arts; art and science; origins; narrative

\section{Introduction}

SIGGRAPH is an acronym that stands for Special Interest Group on Computer Graphics and Interactive Techniques, and it is the organization responsible for one of the most influential conferences on computer image and interaction in the world. The annual conference is eminent not only because of its outstanding quality but also because of its size, which may be around 18,000 attendees every year just in the edition that takes place in North America because it also exists SIGGRAPH Asia. The historical legacy is a critical aspect because it was founded in 1973, although the organization was created in 1969. Today, SIGGRAPH is part of the conferences supported by the ACM, the Association for Computer Machinery.

In the field of art and technology, SIGGRAPH is known because an art gallery was introduced early in the history of the conference, and it has had a significant impact on the art and technology scene in North America and worldwide. Testimony of that influence is the archival work done by Bonnie Mitchell and Jan Searleman who created an online repository of the entire history of the art gallery since 1980 (Mitchell and Searleman 2018). The SIGGRAPH art gallery is comparable to other pioneering exhibitions such as Ars Electronica in Europe; for instance, Ars Electronica started in 1979, and the first art exhibition in SIGGRAPH was in 1980 (see Supplementary Materials). Through the study of the SIGGRAPH Art Gallery history, it is possible to picture the evolution and transformation of the art and technology relationship since the 1980s, especially the interaction between computing, image, and interactivity. The recognition of the exhibitions held as part of the SIGGRAPH framework started in the early eighties when pioneers of the field such as Charles Csuri, David Em, Rebecca Allen, and Barbara Sykes exhibited their works there. As we see the emergence of some relevant media 
artists and the figure of the computational art curator started to take shape; in these early exhibitions enthusiasts and researchers in the field of visual computing such as Dr. Julio Gomez became curators, Gomez was at that time working for NASA JPL implementing some of the first three-dimensional image systems.

In 2018, the conference took place in Vancouver, and the gallery was conceived under the curatorial format, though on some other occasions it has been managed through an Open Call system, therefore my role was that of the Art Gallery Chair and also Art Gallery curator. The task of putting together the art show involved the interaction with the other members of the SIGGRAPH organization, including chairs of related tracks like the Art Papers Chair, the coordination of a section of a publication, the Leonardo Journal SIGGRAPH special issue and more importantly the selection of the artworks that will constitute the exhibition itself organizing a series of artists talks as part of the gallery activities. (see Supplementary Materials)

The SIGGRAPH 2018 Art Gallery was conceived as a dialogical space between cultures, technologies, spaces and worldviews. The title of the exhibition was Original Narratives, addressing a series of questions about the relationship between media and culture that have been inspired by theoretical sources as diverse and as complementary as media archaeology, post-colonial studies, the history of computing, and the social studies of science and technology (Figure 1). The gallery featured contemporary media artworks, digital art pieces by Indigenous communities, and other traces of technologically mediated, creative and ludic practices. As stated in the official communication about the show:

The exhibition aimed to articulate myth and technology, science and art, the deep past and the computational present. Building upon an eclectic selection of creative practices mediated through technologies that represent the complexity and refinement of our times. The venue intended to rekindle the original spark that ignited the collaborative spirit in the community of engineers, scientists, and artists who came together to create our community.

The academic research that I conduct is located at the intersection of three fields: media art history, media archaeology, and the study of the technical unfolding of audiovisual and computational technologies (García Bravo et al. 2017). In various occasions, the results of my academic work have been presented in international conferences such as Media Art Histories, Computer Art Congress, or ISEA (Burbano 2011, p. 135). At the same time, in recent years, my attention has been turned towards art exhibitions because they are a privileged vehicle between theory and practice through which one can propose ideas, stimulate criticism, and connect artists with audiences. In that sense, the opportunity to curate an exhibition such as the SIGGRAPH Art Gallery, which has global visibility, was unique because it allowed me to articulate my academic interests in the history of technology in the exhibition design practice. In this report, I aspire to share with the reader some information and reflections about the curatorial processes, exhibition implementation, and the theoretical concepts and the personal experiences that inspired this show. A complete list of the artists and artworks that participated in the SIGGRAPH 2018 Art Gallery, including the online exhibition, is in Table A1, an appendix to this report (see Appendix A). 


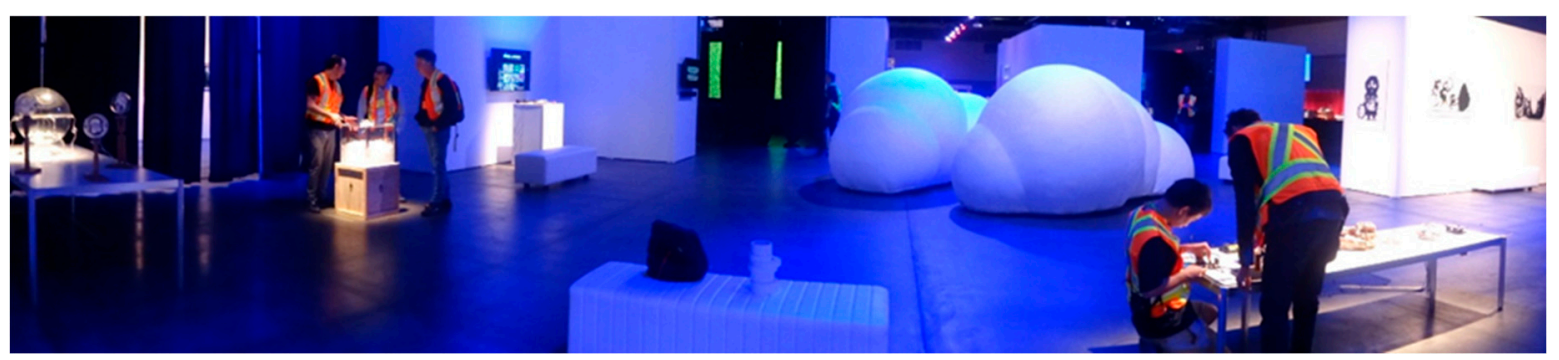

Figure 1. SIGGRAPH 2018 Art Gallery, setup process. Used by permission of Milton Sogabe. Photograph by Milton Sogabe.

\section{The Exhibition}

The curatorial proposal that I developed over 18 months was an invaluable opportunity to connect questions that, in principle, did not seem to form a cohesive discourse. For a long time, I had various cultural, social, and artistic concerns about the exhibition content and the selection process. It was necessary to ask in-depth questions about the meaning of each artwork that could be included in the exhibition. Five areas of interest, or nodes, were articulated in this exhibition: the history of visual computing, the production of new media art by Indigenous communities, the interaction between art and science, projects and artworks that had a thematic association with the curatorial theme, and finally, an online gallery.

The initial approach was focused and diverse at the same time. It was about finding connections between projects of different natures and encountering familiar territories and points of contrast between artworks to build a complex and fruitful dialogue. Fortunately, the communication process with the SIGGRAPH scientific committee, including Chair Roy C. Anthony, was smooth since the very moment he interviewed me to become the Art Gallery Chair, a position that operated under the curatorial format in 2018. At that moment, I emphasized the need to discuss the different cultural realities, the diversity of social groups, and the need to conduct a selection process characterized by a conscious inclusive mindset, which started from a direct and honest relationship with artists, their cultural environments, and their artworks.

\subsection{History of Visual Computing}

Original Narratives attempted to gather some artworks that operate as answers to questions about the origins of computational art, for example, how in some particular historical moments, computers were used to conduct artistic experiments (Patterson 2015). We also delved into the origins of computer aided design, which has had a major impact in the constitution of a community like SIGGRAPH (Franke 2012). For more than ten years now, I have been tracking the genesis of computer graphics, identifying the technologies, the actors, and the researchers working on this field (Burbano 2011). Fortunately, we were able to find one pioneer and one researcher doing substantial investigations on a series of historical projects on computer graphics that seek to explore its roots. A collection of works by Ernest Edmonds compiled under the title Art Systems 1968-2018 and two projects by Daniel Cardoso-Llach under the title Archaeology of CAD were featured as part of the historical node of the show. This node will be developed in depth in the following pages.

\subsection{Digital Media Art by Indigenous Communities}

The technological appropriation and transformation by diverse cultural groups, for instance, the processes driven by Indigenous and Aboriginal communities, were among the main interests of the gallery. It has been one of the primary personal and intellectual engagements in the last decade because I have had the opportunity to interact with members of several Indigenous communities in various countries around the world, including North America (Burbano and García Bravo 2015). In particular, the experience in Canada revealed the cultural wealth of the country concerning Indigenous people, 
Aboriginal cultures, and First Nations. Additionally, the cultural politics of the country facilitate creative manifestations on many fronts, including new media. Therefore, it is pertinent to raise the question about artistic production using technological means by Indigenous communities in Canada, and this was also eventually extended to communities in the United States. Artists working with digital media that belong to the Mohawk, Heiltsuk, Iñupiat, Kānaka maoli, showed their work in the exhibition in an array of manifestations that included experimental video games like "Never Alone" (Upper One Games 2015) (Figure 2) and "A New World" (Nā 'Anae Mahiki and Aboriginal Territories in Cyberspace, 2017), mixed reality installations like "Transformation Mask" (Sean Hunt and Microsoft Garage 2017), and machinima like "She Falls for Ages" (Skawennati 2016). The exploration revealed a robust cultural movement proposing to re-understand the relationship between the Indigenous and the future, the following fragment of the Manifesto for Indigenous Futures (Lewis and Skawennati 2018, p. 422) makes it explicit:

Kiowa author N. Scott Momaday wrote that the 'greatest tragedy that can befall us is to go unimagined.' A great tragedy has already befallen Native people. We live in a society defined by greed for the land and its resources, hate for our cultures and genocide of our peoples. This fact undermines any notion that settler Canadians live in a society that is fair and just for all. It is a foundation that poisons every institution that grows from it. Neither apologies nor reconciliation will rectify it.

The node explored ancient myths, traditional storytelling traversing the digital realm in order to find new audiences. Artists invited to participate were Skawennati, Nā 'Anae Mahiki, Aboriginal Territories in Cyberspace, Shawn Hunt, Microsoft Garage, Dima Veryovka, and Amy Fredeen.

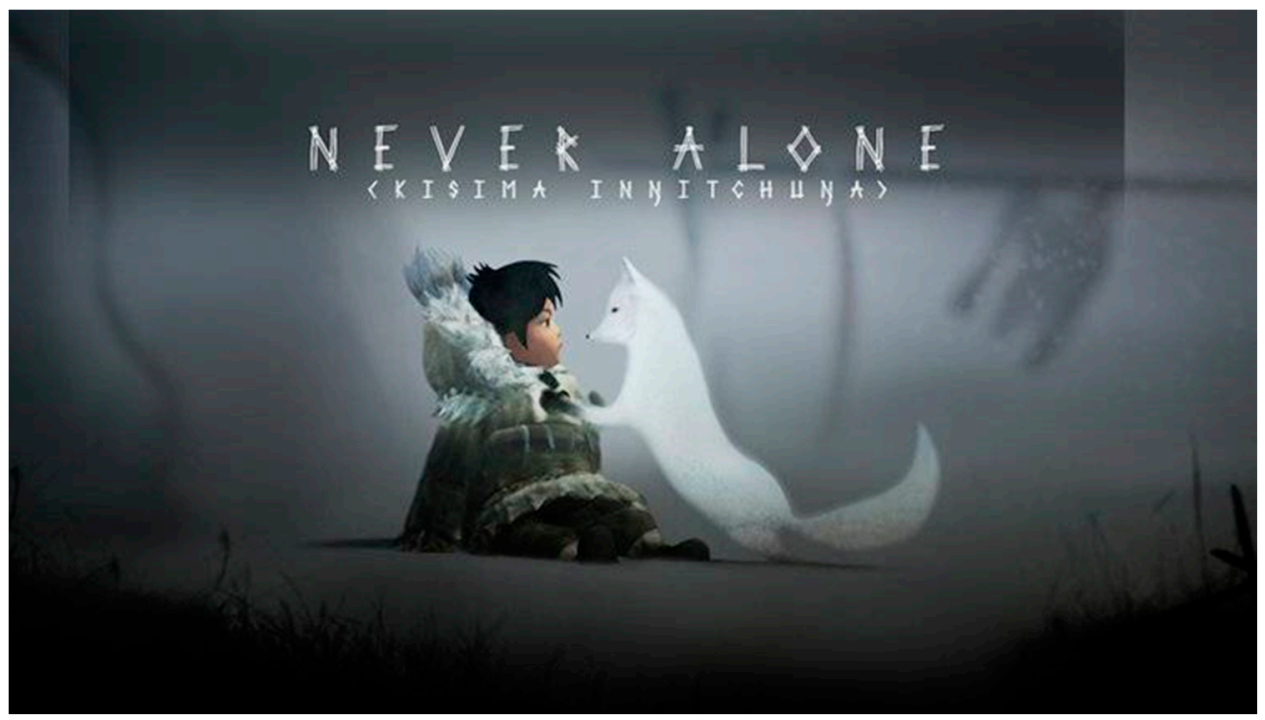

Figure 2. Video game "Never Alone" (2016) by Upper One Games and E-Line Media, based on a traditional Iñupiaq tale. Used by permission of Amy Fredeen and E-Line Media.

\subsection{Art and Science Collaborations}

For the gallery, it was essential also to highlight the interaction between artists and scientists because these transdisciplinary explorations shape some audacious cloverleaves between knowledge and imagination that are transforming the identity of both research and creation today. This fertile ground is manifested in concrete projects that discuss again, with a new perspective, old puzzles like the "Two Cultures" concept (Snow 1959). For the gallery, two remarkable projects were selected, both had to deal with astronomical data, and somehow connecting with the concept of the origins of the cosmos. One was a robotic installation, "Somnium" (Peljhan and team 2016) (Figure 3), that works visualizing and materializing data from the Kepler Space Telescope and the other one is the Virtual 
Reality multiuser installation, "Instrument: One Antarctic Night" (West and team, 2018), that explores data of the cosmos acquired with telescopes located in Antarctica. Both of the projects explored the limits of data representation when confronted to large data sets, using different and original strategies; each project embraced a sincere and dynamic interaction with scientific teams to conceive, develop and finalize the projects. These two projects were funded, in part, thanks to prestigious grants, "Somnium" obtained the support of the SETI institute and "Instrument" the help of the The National Endowment for the Arts. Some artists invited to participate were Marko Peljhan, Danny Bazo, Karl Yerkes for "Somnium", and Ruth West as project leaders and in her team for "Instrument: One Antarctic Night" Violet Johnson, I-Chen Yeh, Zach Thomas, Eitan Mendelowitz, and Lars Berg.

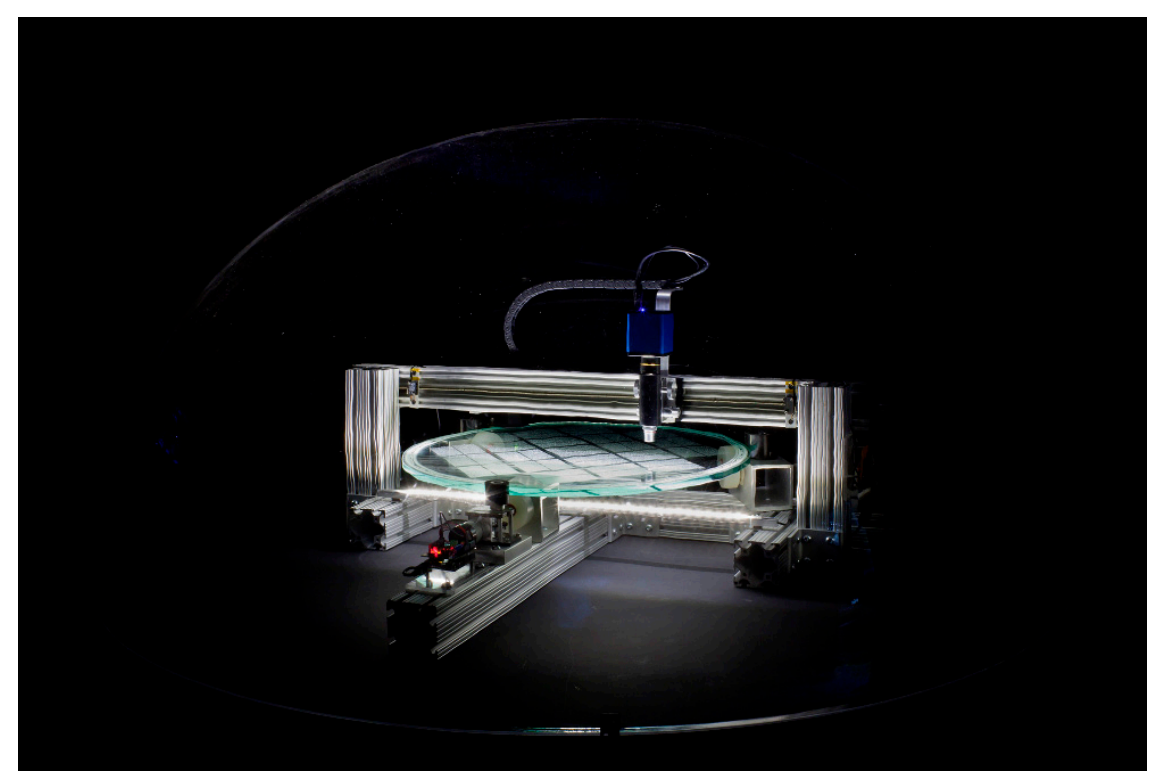

Figure 3. "Somnium" (2016) Robotic installation based on Kepler's Space Telescope data, produced in a SETI Institute residency by Marko Peljhan, Danny Bazo, Karl Yerkes. Used by permission of Daniel Bazo. Photograph by Daniel Bazo.

\subsection{Thematic Connection with the Original Narratives}

In order to guarantee that visitors had a rich and diverse experience, it was necessary to find other artworks that addressed, directly or tangentially, the questions of the origins related to a variety of specific themes; these works came from different contexts. There were two installations related to the origin of energy, "Blow and Touch" (Sogabe, Flogliano and team, 2016) in which the participant generates the necessary electric current to power the systems for the interaction (Figure 4). Another one, "We are the Ocean" (Samanci, 2017) that has to do with the states of mind, the origins of emotions, in order to transform a real-time tridimensional scene using a Brain-computer interface (BCI). The other two projects were exceptional in their own right. One was specially produced for the show "Heaven" (Beim and team, 2018) an immersive analog installation by a renowned company focused on tangible interaction, this installation invited the audience to go inside a soft cloud that recreates the process of being born, and the last one was somehow the antipode of the gallery theme because it had to do not with origins but with endings, in this case, an installation that works with materials that come from the destruction caused by earthquakes, "Diastrophisms" (L'Huillier and team, 2017). Artists invited to participate in this node were the cAt Research Group, Milton Sogabe, Fernando Fogliano, Ozge Samanci, Gabriel Caniglia, Alex Beim, Tangible Interaction, Nicole L'Huillier, Yasushi Sakai, and Thomas Sanchez. 


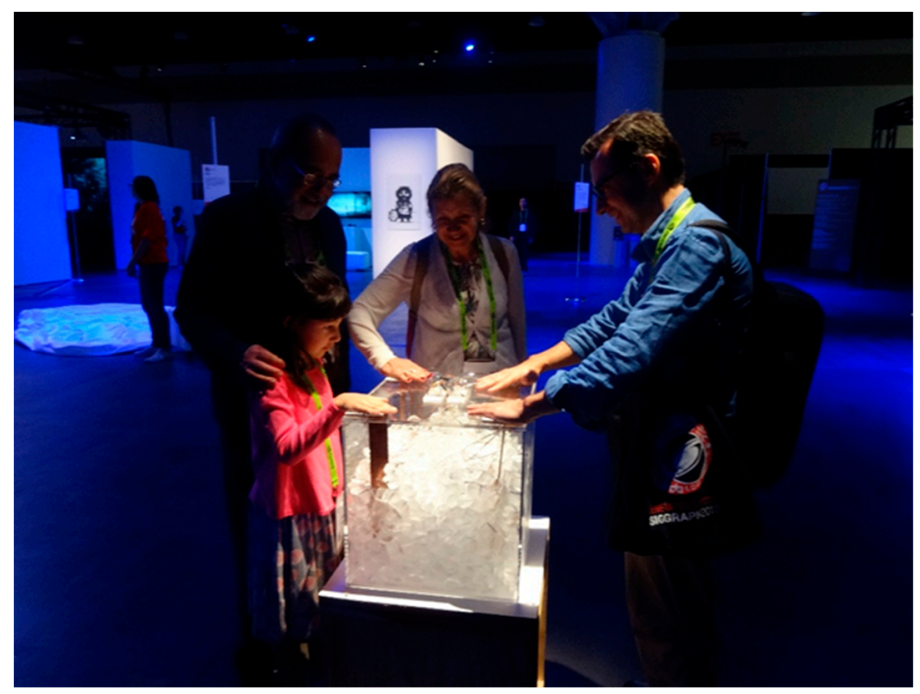

Figure 4. "Toque" (2016) produced by the cAt Research Group, Milton Sogabe, Fernando Fogliano and team. Photograph by Milton Sogabe. Used by permission of Milton Sogabe.

\subsection{Origins + Journeys Online Gallery}

The gallery also included an online component, it was not a translation of the gallery content, but a different and complementary project that shared a thematic link with the galley while adding some more conceptual and experimental textures, the online exhibition was entitled "Origins + Journeys". It operated with an Open Call system and was a collaboration with Vistoria E. Szavo from the Digital Arts Community, a vital organization within SIGGRAPH. The DAC has a weighty tradition in the field of online exhibitions, which opened the space to something that will last over time and that had a distinctive identity, it is still available in the following URL: http://origins-journeys.siggraph.org. The virtual gallery was conceived and developed with the artist and curator Victoria Szavo. The artists who were selected were Yucef Merhi, Carlos Rosas, Cynthia Beth Rubin, Kris Tonski, Yona Verwer, Ella Husbands, Daniel Pillis, Albert Barqué-Durán, Marc Marzenit, Elisa Ferrèand, Quo Artis Foundation, Anna Ursyn, Robert Ehle, Yuan-Yi Fan, Jennifer Zaylea, Esteban Gutierrez, Volker Kuchelmeister, and Francesca Franco (see Supplementary Materials).

The project "Algorithmic Signs-Five pioneers of computer art in conversation" by Italian curator Francesca Franco was remarkable because it was an online documentary about an art exhibition at the gallery Bevilacqua La Masa Foundation in Venice where five of the most important pioneers of computer arts shared the space: Vera Molnar, Manfred Mohr, Roman Verostko, Frieder Nake, and, very important for the SIGGRAPH Art Gallery, Ernest Edmonds. The documentation of this show was included in the online art gallery because it connects well with the historical interest of the SIGGRAPH Art Gallery in general terms.

\section{Materials and Methods}

The curatorial process was based on multiple methods ranging from the studio visits, laboratories visits, interviews, review of offline and online portfolios, to direct interaction with artists to conceive new works, to propose changes to works in development or to suggest ways to present existing projects with the aim to fine tune them for the discursive scope of the exhibition. The show was produced in 18 months, in which a group of artworks was identified that have to do with the arguments proposed above. The dynamic interaction with the artists was a vital aspect of the curatorial process to communicate the ideas and to understand the need to interconnect the contents and discourses of the works. Kittler's words about the new understanding of museums and galleries based on computer architecture was helpful to this process (Kittler 2017, p. 74). I paraphrased his ideas in the presentation of the SIGGRAPH 2018 Art Gallery: 
the future of the museum - and by extension, the future of the gallery and the exhibition -is discussed in terms of its relationship to computers. He argues that rather than asking if computers have a place in the museum, curators should instead ask how the various components of computers can be used as an organizational metaphor for museum activities. The computer's memory can be understood as the museum's archives, the computer's access to a network can be understood as the distribution of knowledge to the public, and the computer's many processing operations can be understood as the various aspects of the curatorial process.

At the methodological level, one of the ideas used during the conception of the exhibition was the development of a small software package that allowed the articulation of a series of descriptors and meta tags in order to find elements that the artwork had in common. This raised a series of initial concerns. It was a productive process that was set aside by the team. The development of the software to assist curatorial processes has potential; in this case, it was an experiment. It is possible that shortly, we will have access to tools that will assist the curatorial selection process at a computational level. These kinds of initiatives must be contextualized within previews curatorial works related to new media art made by Christiane Paul, Rudolf Frieling, and Benjamin Weil (Cook and Graham 2010).

Another front where a systematic approach was necessary was the strategy to interconnect several arts-related initiatives inside SIGGRAPH. The first was the idea to collaborate with the Lifetime Achievement in Digital Art Award coordinated by Sue Gollifer. The second was a collaboration with the Art Papers track led by Angus Forbes. We invited to the exhibition one of the artists who wrote one remarkable paper about her work on the remains of earthquakes and media (Forbes 2018). The third was a collaboration with the Digital Arts Community (DAC) to put together the aforementioned online exhibition, and the last one was a collaboration with the Leonardo organization. The Leonardo Journal publishes a SIGGRAPH Special Issue every year featuring the Art Papers and Art Gallery content. In this case, we went beyond framing the gallery as a tribute to the Leonardo 50th anniversary, giving public recognition to two young artists who represent the future of the field Mirjana Prpa and Nicole L'Huillier, among other things.

\section{History of Computer Arts and Computer-Aided Design}

The academic work I conduct tracks some of the earlier interactions between computers, images, and media identifying case studies in multiple cultural scenarios on this field, theoretical frameworks coming from media archaeology, media art histories, and science and technology studies play an important role in the description and interpretation of the technologies studied (Burbano 2011, p. 140). Let us focus now on one of the five constituent components of the exhibition, which is the historical node, given its relevance for this issue of the journal. This node articulated two different threads. On the one hand, there is an interest in the history of computing, and the place that the origins of computational art occupy in that history (Kane 2014). On the other hand, there is the attention to the history of the software and hardware devices that account for the conception and implementation of the Computer-Aided Design.

\subsection{Art Systems 1968-2018}

To set the tone of the exhibition, it seemed fundamental to invite one of the pioneers of the arts and computing scene, we were fortunate to have the participation of Ernest Edmonds (1942). He is one of those creative spirits who shaped the practice and a representative of the generation who gave shape the earliest community linking computational technology and creativity in the second half of the 20th century; his work is as relevant as those by Vera Molnar, Georg Nees, or Harold Cohen (Nake 2009). In SIGGRAPH 2017 in Los Angeles, the year before the exhibition in Vancouver, Edmonds had been awarded the ACM SIGGRAPH Distinguished Artist Award for Lifetime Achievement in Digital Art (Gollifer 2016, p. 354). These SIGGRAPH awards, which have worldwide relevance, do not necessarily show the work of the artists who received the distinction therefore it seemed to me that an essential 
task was to connect those two initiatives. The first action was to get in touch with Edmonds to see the possibility of including a sample of his work within the SIGGRAPH 2018 Art Gallery (Figure 5). Fortunately, the communication with him was smooth and productive; he accepted the invitation, and it was decided to include several of his pioneering works and some more recent ones in the exhibition. It is crucial to be able to display this type of works in events such as SIGGRAPH which look permanently into the future, thus contributing by exposing historical content that complements and contrasts the perspective of the new technological media. The importance and density of Edmond's reflections about arts, computation and aesthetics are presented and discussed in the book he wrote with Margaret Boden From Fingers to Digits: An Artificial Aesthetic about the relationship between computation and creativity, many of their insights illuminate the practical work he developed in those early years, and more importantly those ideas are also valid in the present times for the Artificial Intelligence and the Arts context, for instance (Edmonds and Boden 2019, p. 83). Additionally, the recognition of the work by Edmonds is confirmed with the recent publication of a book dedicated to his creative and intellectual trajectory Generative Systems Art by Francesca (Franco 2017).

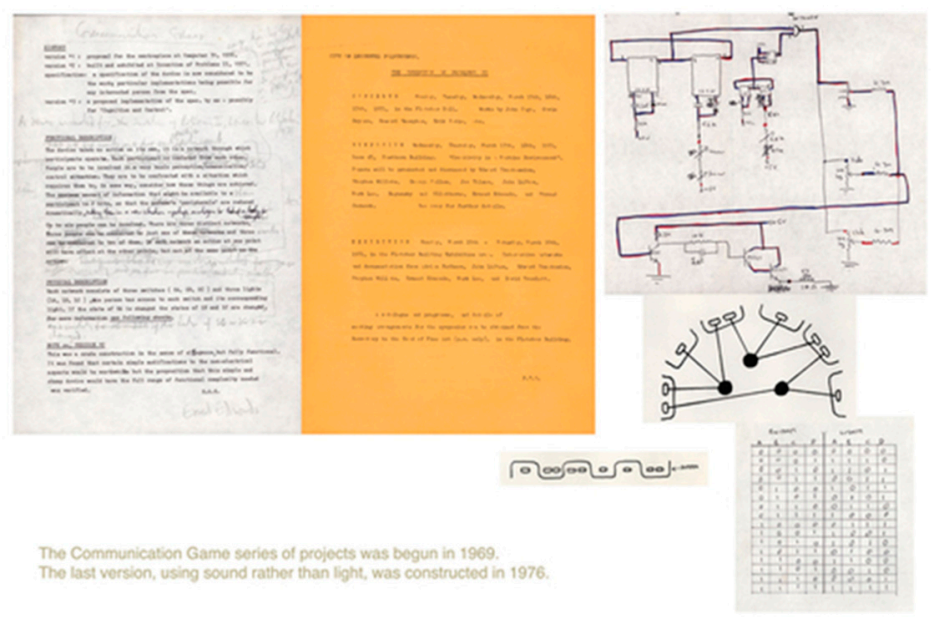

Figure 5. "The Communication Game" (1969) by Ernest Edmonds. Used by permission of Ernest Edmonds.

Five artworks by Edmonds were included, some of which he created in the late sixties and the early seventies, such as "Nineteen" (Edmonds 1968), "Datapack" (Edmonds 1969), and "Communication Game" (Edmonds 1972), these artworks are of fundamental importance since they determine several foundational concepts of what will be known as the computational art. In other words, they anticipated some of the different facets of computational art like the relationship between code, computation and artificial creativity. These artistic projects were beyond just displaying graphics on a screen; what they did were processes like delivering instructions to organize the physical elements of one artwork, giving guidelines to use hardware devices, or establishing the rules of ludic communication experiments. These three historical works pose a series of possibilities that make evident the rich source of the application of algorithmic logic to creative practice. Edmonds explored the theories of information and communication in vogue at that time in a practical way, creating artworks with overwhelming depth (Edmonds 2018, p. 428). His works were also included because some of the pieces had to do with the origin of animation, of the moving image at the computational level. Some of the first moving graphics that were developed in computers, short geometric sequences, which are fundamental since the community in SIGGRAPH has been created around the production of short- and full-length animation films.

It was also decided to include two recent pieces by Edmonds; one of them, "Shaping Form" (Edmonds 2002), works with a camera as an input device, but unlike other similar pieces, it does not define the form of what is captured with the camera and instead translates the image produced by the 
movement of the public in a specific color palette (Edmonds 2018). Finally, as a sign of the importance of the recent work of Edmonds, a new project was included, "H Space" (Edmonds and team 2018), in which he works with the Microsoft HoloLens. This piece was developed with a team working in China, and Yingqing Xu, Xin Tong, YI JI and Damian Hills were in charge of the technical development; the team had the opportunity to come to Vancouver to show this augmented reality experience in the gallery (Figure 6). Therefore, the gallery had two pieces working with the Microsoft HoloLens. The other one was "Transformation Mask," a collaboration between Shawn Hunt and the Microsoft Garage team in Vancouver.

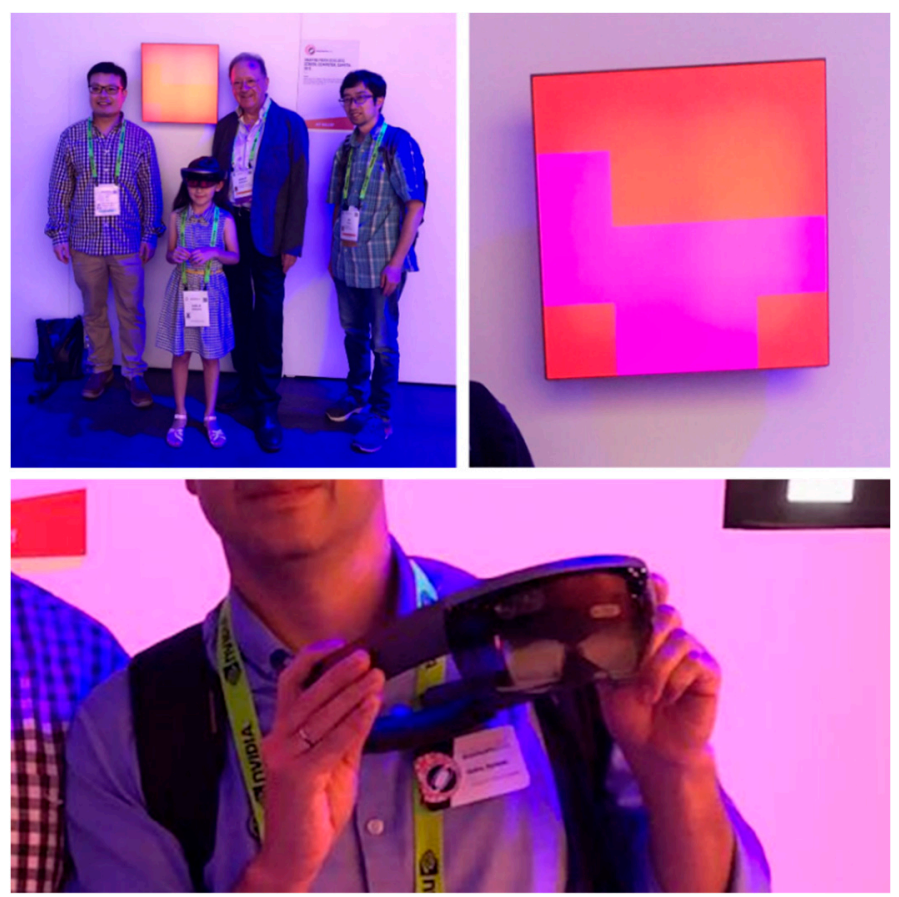

Figure 6. "H Space" (2018) by Ernest Edmonds in collaboration with Yingqing Xu, Xin Tong, YI JI and Damian Hills. Used by permission of Milton Sogabe. Photographs by Milton Sogabe and Andres Burbano.

It is worth mentioning that these pioneering and new works were shown with a selection of the papers that had been published by Edmonds and some collaborators around the early seventies in the Leonardo Journal (see Supplementary Materials). Here is an essential topic of the exhibition that allows us to connect with the history of the Leonardo Journal itself, which, for more than 50 years now, has served as a platform for the discussion of cutting-edge ideas about art, technology, and science. The whole exhibition was a tribute to the 50th anniversary of the Leonardo Journal, which was founded by the scientist and artist Frank Malina (Burbano 2018, p. 420). The legacy of Malina and the other founders of the magazine reminds us, importantly, that the creators who are interested in these transdisciplinary practices need opportunities to publish in order to circulate ideas and share experiences in order to find resonances in their communities (Forbes 2018, p. 332).

\subsection{Archaeology of CAD: Interactive Software Reconstructions of the Coons Patch and Sketchpad}

While searching for academic documentation about the history of Computer-Aided Design, it is possible to find appealing and deep bibliographic material. However, on many occasions, those materials tend to be more descriptive than analytic because they present technical aspects without discussing the socio-cultural contexts (Peddie 2013, p. 6). In such a scenario, the research and publications by Daniel Cardoso-Llach are exceptional because he makes a significant effort to find a balance between those two fields. The testimony of his approach is in his book Builders of the Vision: 
Software and the Imagination of Design, which is a monographic volume dedicated to the history of CAD, the implementations of it in the domains of design, architecture, and urban planning with an emphasis in a science and technology studies perspective (Cardoso-Llach 2015, p. 49). Parallel to his scholarly work Cardoso-Llach engages with practical implementations in order to understand the computational aspects of the historical case studies, in other words, he recreates the old technical systems with new tools in order to understand their technical ontology. Such technical reenactments are a crucial part of his methodology, in the SIGGRAPH 2018 Art Gallery examples of these reconstructions were included, these installations have been developed at the Computational Design Laboratory at Carnegie Mellon University by Cardoso-Llach, with the help of Scott Donaldson and Harshavardan Kedia.

Cardoso-Llach, as part of his research and beyond his activity as writer, researcher and creator of technical reconstructions, produces shows based on historical materials, artifacts, and primary sources, one example is the exhibition "Designing the Computational Image, Imagining Computational Design" at the Miller Gallery at Carnegie Mellon University (2017), he developed this prominent exhibition that had an important impact on the scene of computational media history. Two of the projects that were developed for that exhibition were invited to take part for the SIGGRAPH 2018 Art Gallery.

"Sketchpad" reconstruction (Cardoso-Llach 2017). The work of Ivan Sutherland is considered a turning point in the field of computer graphics; his achievements in vector-based images generated and processed by digital machines are uncontested because of the clarity at the conceptual level and the resourcefulness at the implementation level. This is evident because of the impact of his software-hardware thesis "Sketchpad," written in 1962, which includes no doubt, one of the most influential pieces of code ever written. However, the interaction with the "Sketchpad" itself is minimal; only a few people had the opportunity to draw directly with the original piece of software and hardware. The research by Cardoso-Llach goes deep into the original computational ideas and the technical recreation of both software and hardware. The recreation of the "Sketchpad" was present in the gallery and got the attention of the visitors because of its important cultural legacy (Figure 7).

"Coons Patch" reconstruction (Cardoso-Llach 2017). Also in the early sixties, Steven Coons developed the "Coons Patch," a software that was very creative at the mathematical level and was able to computationally represent and manipulate surfaces, that is, their geometric plasticity and structure. The Coons Patch allowed the creation of smooth surfaces between defined curves. The reconstruction done by Cardoso-Llach enables the design and transformation of surfaces in real time to appreciate their geometric characteristics and explore their mathematical concepts (Figure 8).

The projects developed by Cardoso-Llach make evident the need for interacting with the physicality of the devices again. It is determinant that these devices are in action again; the idea is not to have exact replicas but artifacts that operate as historical machines that operate as models of what happened, and those models open the door for novel interpretations. Researcher Matthew Allen describes the exhibitions run by Cardoso-Llach in the following way (Allen 2018, p. 424):

In its pairing of historical and contemporary material, Designing the Computational Image shows that computer-aided has a pronounced legacy in aesthetics. The image-making practices and visual conventions developed half a century ago are now firmly lodged in the collective imagination of design. In my field, architecture, everyone now uses computers; students today are being enculturated to appreciate computational images even if they have no particular passion for long-obsolete technologies. Reinterpreting the history of computer-aided design as an aesthetic movement is thus crucial to maintaining its resonance with the present. Cardoso-Llach's exhibition has shown that the images on display still resonate strongly. 


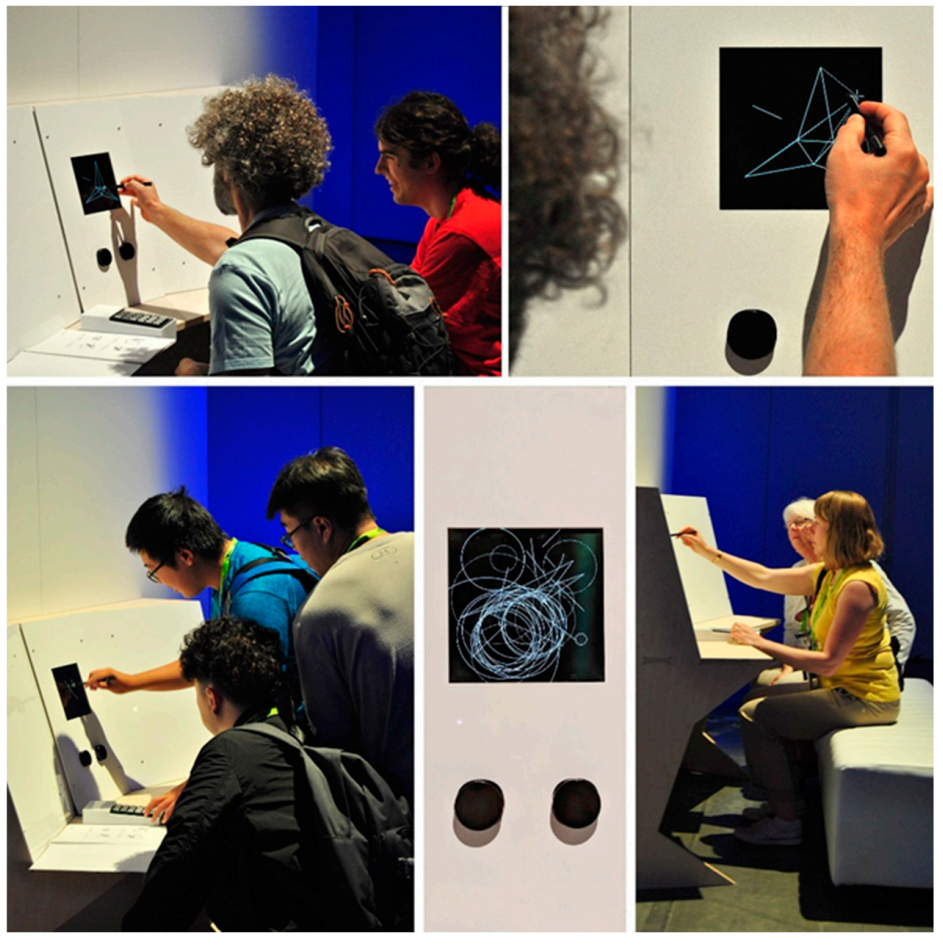

Figure 7. "Sketchpad" reconstruction by Daniel Cardoso-Llach. Used by permission of Daniel Cardoso-Llach. Photographs by Daniel Cardoso-Llach.
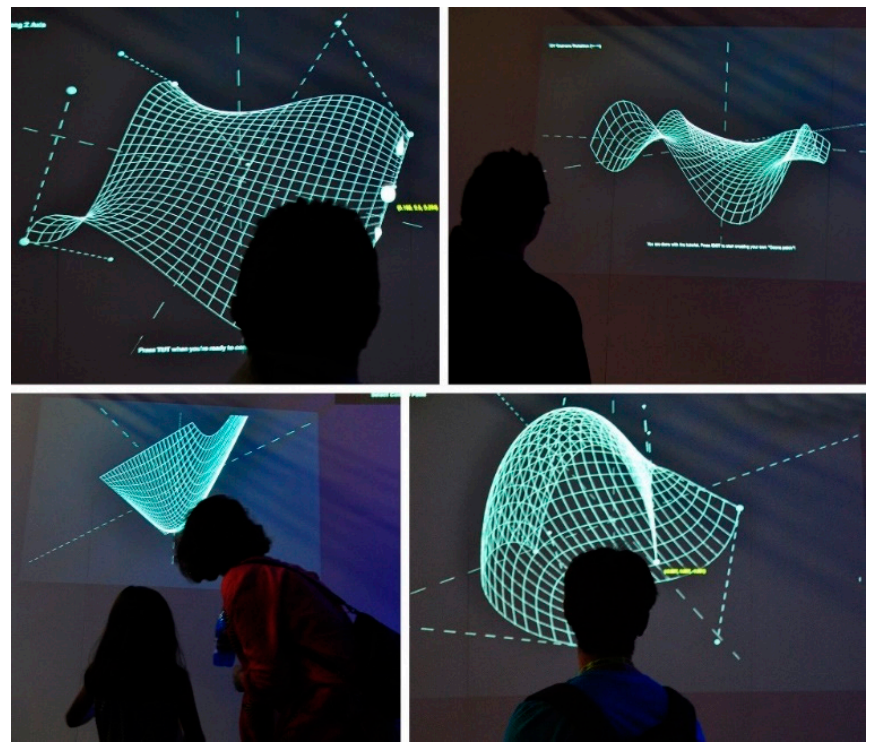

Figure 8. "Coons Patch" reconstruction by Daniel Cardoso-Llach. Used by permission of Daniel Cardoso-Llach. Photographs by Daniel Cardoso-Llach.

\section{Discussion}

The theme "Original Narratives", as well as the many questions around the origins as a conceptual framework present in different fields and the ways how these origins must be narrated, operated as a common ground through the five instances of the exhibition presented above. The theme worked as a unifying factor for the exhibition. Therefore, different approximations articulate questions to go from the genesis of computer art to scientific processes that describe the beginnings of things, 
such as the origins of the cosmos, the origins of life, exposing a considerable potential when offering enriched readings.

The historical node articulated artworks that can be seen as answers to the genealogies of computational art, describing how, in some particular moments, computers were used to draw graphs and conduct artistic experiments. In this case, the gallery also delves into the origins of CAD, which has had a significant impact on the constitution of a community like SIGGRAPH. At the entrance of the exhibition, the gallery welcomed the public with the aforementioned pioneering works by Ernest Edmonds, his publications, and some more recent projects, including one that was still under development-presenting in this show the vast scope of the creative world of the artist while exposing the ability that he has to use novel technologies. The reader might think that after seeing this small retrospective of an artist of these dimensions, it was challenging to maintain the quality of the exhibition, but on the contrary, a series of unexpected relationships were established with the rest of the contents of the exhibition.

An exhibition as diverse as the SIGGRAPH Art Gallery 2018 emphasizes what Kittler understands as the "processing of data" in a museum, and by extension in an exhibition, as a similar process to curating (Kittler 2017, p. 69). In other words, the gallery articulates characteristics of works that operate as connectors or as elements with the capacity to generate contrasts. An exhibition like this, which does not have a univocal thematic obligation, which does not intend-for example-to narrate the historical trajectory of an artist, has the freedom to pose threads of thematic tension that interweave sense articulating conceptual elements and experiential aspects. That is to say, the discursive thread of the exhibition is as important as the experience design. In this way it is possible to start a dialogue, to discuss artworks and groups of artworks that run with different technologies, which come from dissimilar periods and that emphasize discursive elements that are peculiar to themselves. This experience shows that the understanding of artworks as abstract elements close to information or data facilitates the processes of constructing routes and trajectories within the exhibition space at the time of proposing a curatorship and making the curatorial design (Figure 9).

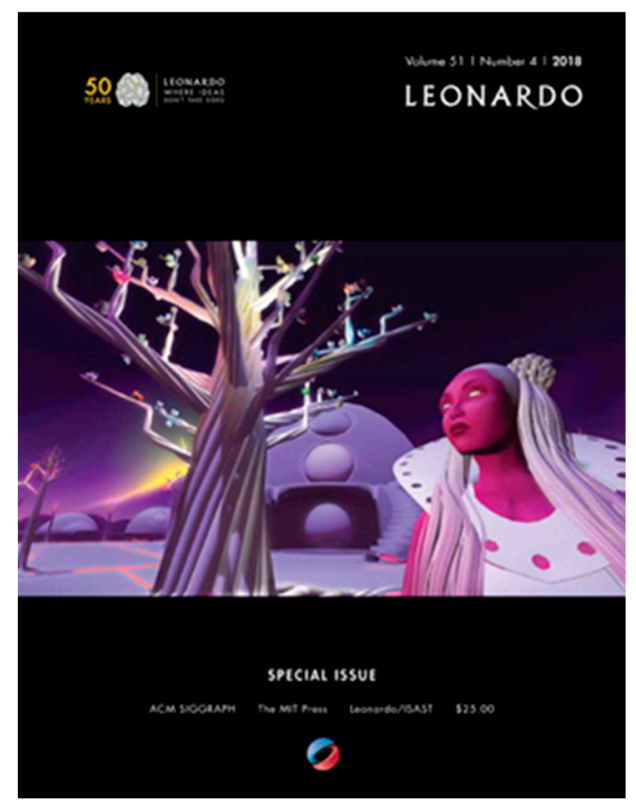

Figure 9. Leonardo Journal SIGGRAPH 2018 Special Issue, cover image "She Falls for Ages" (2017) by Skawennati. Used by permission of Skawennati and MIT Press.

Supplementary Materials: The following materials are available online (1) SIGGRAPH 2018 Art Gallery website: https://s2018.siggraph.org/conference/conference-overview/art-gallery/; (2) SIGGRAPH 2018 Art Gallery video trailer: https://youtu.be/H-I7aYVgRJ8; (3) “Origins and Journeys" on line exhibition: http://origins-journeys. 
siggraph.org/wp/; (4) Leonardo SIGGRAPH 2108 Special Issue: https://www.mitpressjournals.org/toc/leon/51/4;

(5) SIGGRAPH Art Gallery Archive: https://digitalartarchive.siggraph.org/.

Funding: ACM and SIGGRAPH entirely founded the SIGGRAPH 2018 Art Gallery.

Conflicts of Interest: The author declares no conflict of interest.

\section{Appendix A}

Table A1. Complete list of artists, artworks and projects that participated in the SIGGRAPH 2018 Art Gallery curated by author.

\begin{tabular}{|c|c|}
\hline Artists, Laboratories & Artworks, Projects \\
\hline \multicolumn{2}{|c|}{ History of Visual Computing Node } \\
\hline $\begin{array}{l}\text { Ernest Edmonds, De Montfort University. "H Space" team: } \\
\text { Yingqing Xu, Xin Tong, YI JI, and Damian Hills. }\end{array}$ & $\begin{array}{c}\text { Nineteen (1968), Datapack (1969), Communication Game } \\
\text { (1972), Shaping Form (2002), and H Space (2018), premiere } \\
\text { All these artworks are directly related to papers published } \\
\text { in Leonardo since 1973. }\end{array}$ \\
\hline $\begin{array}{c}\text { Daniel Cardoso-Llach, Carnegie Mellon University. Scott } \\
\text { Donaldson, iStrategyLabs. }\end{array}$ & $\begin{array}{c}\text { Archaeology of CAD: Interactive Software Reconstructions } \\
\text { of the "Coons Patch" and "Sketchpad." }\end{array}$ \\
\hline \multicolumn{2}{|c|}{ Digital Media Art by Indigenous Communities Node } \\
\hline Skawennati. & She Falls for Ages (2016). \\
\hline Nā 'Anae Mahiki - Aboriginal Territories in Cyberspace. & He Ao Hou, A New World (2017). \\
\hline $\begin{array}{l}\text { Shawn Hunt, Independent Artist. Microsoft Garage team: } \\
\text { Robert Butterworth, Jeremy Kersey, Andy Klein, Julia } \\
\text { Taylor-Hell, Jonathan Cobb, Brent Silk, Brendan O'Rourke, and } \\
\text { Stacey Mulcahy. }\end{array}$ & Transformation Mask (2017). \\
\hline $\begin{array}{l}\text { Amy Fredeen, Cook Inlet Tribal Council. Dima Veryovka, } \\
\text { E-Line Media, and Upper One Games. }\end{array}$ & $\begin{array}{c}\text { Never Alone (Kisima Innitchuna): The Art and the People of } \\
\text { the Story (2016). }\end{array}$ \\
\hline \multicolumn{2}{|c|}{ Art and Science Collaborations Node } \\
\hline $\begin{array}{l}\text { Danny Bazo, Meow Wolf. Marko Peljhhan UCSB, Projekt Atol } \\
\text { Institute. Karl Yerkes, UCSB. }\end{array}$ & Somnium (2016). \\
\hline
\end{tabular}

Ruth West, University of North Texas, xREZ Art + Science Lab.

Violet Johnson, University of North Texas, xREZ Art + Science

Lab. I Chen Yeh, University of North Texas, xREZ Art +

Science Lab. Zach Thomas, University of North Texas, xREZ

Art + Science Lab. Eitan Mendelowitz, Mount Holyoke College. Lars Berg, Independent Artist.

\begin{tabular}{|c|c|}
\hline \multicolumn{2}{|c|}{ Thematic Connection with the Original Narratives Node } \\
\hline $\begin{array}{c}\text { Ozge Samanci, Northwestern University. Gabriel Caniglia, } \\
\text { Northwestern University. }\end{array}$ & You Are the Ocean (2017). \\
\hline $\begin{array}{l}\text { Milton Sogabe, São Paulo State University. Fernando Luiz } \\
\text { Fogliano, University of São Paulo. Fabio Oliveira Nunes, } \\
\text { UNESP. Carolina Peres, UNESP. Soraya Braz, UNESP. Rodrigo } \\
\text { Dorta, UNESP. Cleber Gazana, UNESP. Mirian Steinberg, } \\
\text { UNESP. Melina Furquim, UNESP. Daniel Malva, UNESP. }\end{array}$ & Sopro and Toque (The Blow and Touch) 2016. \\
\hline $\begin{array}{l}\text { Nicole L’Huillier, MIT/Media Lab. Yasushi Sakai, MIT/Media } \\
\text { Lab. Thomas Sanchez Lengeling, MIT. }\end{array}$ & Diastrophisms, (2017). \\
\hline Alex Beim, Tangible Interaction. & Haven (2018), premiere. \\
\hline \multicolumn{2}{|c|}{ Origins and Journeys Online Exhibition Node } \\
\hline Volker Kuchelmeister, UNSW University of New South Wales. & Topography of the Unseen. \\
\hline Esteban Gutiérrez, FUBA. & Occupation. \\
\hline Leslie Nobler, William Paterson University. & Roots, Journeys, Diaspora and Refuge. \\
\hline Jennifer Zaylea, University of the Arts. & Deconstruct to Reconstruct. \\
\hline Yuan-Yi Fan, yuanyifan.com. & Structural Analogy. \\
\hline
\end{tabular}


Table A1. Cont.

\begin{tabular}{cc}
\hline Artists, Laboratories & Artworks, Projects \\
\hline Francesca Franco, University of Exeter. & Dot. \\
\hline $\begin{array}{c}\text { Anna Ursyn, University of Northern Colorado; Robert Ehle, } \\
\text { University of Northern Colorado. }\end{array}$ & $\begin{array}{c}\text { Algorithmic Signs-Five Pioneers of Computer Art in } \\
\text { Conversation. }\end{array}$ \\
\hline $\begin{array}{c}\text { Albert Barqué-Durán, Quo Artis Foundation; Marc Marzenit, } \\
\text { Quo Artis Foundation; Elisa Ferrè, Vestibular Multisensory } \\
\text { Embodiment, Royal Holloway University of London. }\end{array}$ & The Zero-Gravity Band. \\
\hline Daniel Pillis, Carnegie Mellon University. & A Brief History of Computer Graphics. \\
\hline Ella Husbands, Independent Artist. & Embodied Distortion. \\
\hline $\begin{array}{c}\text { Cynthia Beth Rubin, C B Rubin Studio; Kris Tonski, Fusion } \\
\text { Design; Yona Verwer, YV Studio. }\end{array}$ & Zodiacs in the Lower East Side. \\
\hline Carlos Rosas, The Pennsylvania State University. & “Unsettled Interlude | Origin: $45.79835^{\circ},-92,36738^{\circ},$. \\
\hline Carlos Rosas, The Pennsylvania State University. & “Unsettled Drift | Origin $44.981397^{\circ},-93.150807^{\circ}$. \\
\hline Yucef Merhi, Independent Artist. & Quetzalcoatl 2.0.1.2.
\end{tabular}

\section{References}

Allen, Matthew. 2018. The computational imagination: Notes on the exhibition designing the computational image, imagining computational design. Leonardo 51: 424-25. [CrossRef]

Burbano, Andres. 2011. Between Punched Film Stock and the First Computers. In ReLive: Media Art Histories. Edited by Sean Cubitt and Paul Thomas. Cambridge: The MIT Press.

Burbano, Andres. 2018. Original narratives art gallery: Introduction. Leonardo 51: 420-21. [CrossRef]

Burbano, Andres, and Esteban García Bravo. 2015. Breaking the Navajo code with Bill Toledo. Artnodes, 26-33. [CrossRef]

Cardoso-Llach, Daniel. 2015. Builders of the Vision: Software and the Imagination of Design. New York: Routledge.

Cook, Sarah, and Beryl Graham. 2010. A Brief History of Curating New Media Art. Berlin: The Green Box.

Edmonds, Ernest. 2018. Art systems: 1968 to 2018. Leonardo 51: 426-28.

Edmonds, Ernest, and Margaret Boden. 2019. From Fingers to Digits: An Artificial Aesthetic. Cambridge: The MIT Press.

Forbes, Angus. 2018. Art papers jury: Introducing the SIGGRAPH 2018 art papers. Leonardo 51: 332-35. [CrossRef]

Franco, Francesca. 2017. Generative Systems Art: The Work of Ernest Edmonds. New York: Routledge.

Franke, Herbert. 2012. Computer Graphics-Computer Art. Berlin: Springer Science \& Business Media.

García Bravo, Esteban, Andres Burbano, Vetria Byrd, and Angus Forbes. 2017. The interactive image: A media archaeology approach. Leonardo 50: 368-75.

Gollifer, Sue. 2016. ACM SIGGRAPH distinguished artist award for lifetime achievement in digital art. Leonardo 50: 354-55. [CrossRef]

Kane, Carolyn L. 2014. Algorithms: Synthetic Color, Computer Art, and Aesthetics after Code. Chicago: University of Chicago Press.

Kittler, Friedrich. 2017. No hay software y otros ensayos sobre filosofía de la tecnología. Manizales: Universidad de Caldas.

Lewis, Jason Edward, and Skawennati. 2018. The future is Indigenous. Leonardo 51: 422-23. [CrossRef]

Mitchell, Bonnie, and Jan Searleman. 2018. ACM SIGGRAPH Art Shows Archive. Available online: https: //digitalartarchive.siggraph.org/ (accessed on 11 January 2019).

Patterson, Zabet. 2015. Peripheral Vision. Cambridge: The MIT Press.

Peddie, Jon. 2013. The History of Visual Magic in Computers: How Beautiful Images are Made in CAD, 3D, VR and AR. London: Springer.

Snow, C.P. 1959. The Two Cultures. New York: Cambridge University Press.

(C) 2020 by the author. Licensee MDPI, Basel, Switzerland. This article is an open access article distributed under the terms and conditions of the Creative Commons Attribution (CC BY) license (http://creativecommons.org/licenses/by/4.0/). 